\title{
THE INFLUENCE OF THE META-STABLE TRIPLE POINT SOLUTION OF MONOCALCIUM PHOSPHATE MONOHYDRATE UPON THE CLAY SEPARATES OF TWO ONTARIO SOILS ${ }^{1}$
}

\author{
A. F. MacKenzie and C. A. Campbell ${ }^{3}$
}

[Received for publication March 29, 1962]

\begin{abstract}
Samples of material less than $2 \mu$ in diameter were obtained from the surface horizon of a Guelph loam and of a Haldimand clay loam. These samples were subjected to six successive treatments with the meta-stable triple point solution of monocalcium phosphate monohydrate (MTPS) to simulate the environment near a dissolving superphosphate granule. Samples of montmorillonite and illite standard clays were also included. The dissolution losses in per cent were: Guelph clay 59.5, Haldimand clay 40.4 , montmorillonite 3.4 , and illite 8.1. Total chemical analyses, X-ray diffraction techniques, differential thermal analyses and electron microscope observations were used to determine the nature of these losses. In the soil clay separates, vermiculite and interstratified montmorillonite were more susceptible to the action of MTPS than were the illite or halloysite clay minerals.
\end{abstract}

\section{INTRODUCTION}

When a granule of superphosphate dissolves in soil the solution leaving the granule closely approximates the meta-stable triple point solution of monocalcium phosphate monohydrate (MTPS) $(11,12)$. The amounts of iron, aluminium and manganese that have been found in this solution indicate a rather drastic reaction with the soil $(13,14)$. The source of some of these dissolved compounds may be the clay minerals. Investigations with dilute phosphorus solutions have indicated the instability of kaolinite, illite and other clay minerals in these solutions $(4,5,17,19,23)$. Research indicates that, if a clay has a particular solubility, then the removal of soluble iron and aluminium as insoluble phosphates causes further solution of the clay mineral $(15,8,10)$. This effect is difficult to predict because of the slow establishment of equilibrium in silicates (20). The objective of this study was to determine the effect of MTPS on the total and differential destruction of naturally-occurring soil clay separates.

\section{MATERIALS AND METHODS}

Air-dried soil samples from the surface horizons of a Guelph loam and Haldimand clay loam were selected because previous work indicated a difference in the proportion of clay types present, the Haldimand clay separate being more illitic (24). The samples were treated with sodium acetate buffer of $\mathrm{pH} 5.0$ to remove carbonates and exchangeable cations. Organic matter was removed by oxidation with hydrogen peroxide. The soil was washed free of excess salts and dispersed with the aid of a commercial preparation of sodium poly-meta phosphate. The clay fraction, less than 2 microns in diameter, was collected by sedimentation and dried on a steam plate.

The MTPS was prepared using the method described by Lindsay, Lehr and Stephenson (14). The $\mathrm{pH}$ of 1.47 and density of $1.27 \mathrm{~g} . / \mathrm{cc}$. agreed closely with values recorded for this solution.

${ }^{1}$ Contribution from the Department of Soil Science, Ontario Agricultural College, Guelph, Ont.

Assistant Professor, Department of Soil Science, Macdonald College of McGill University, Macdonald College, Que.

GGaduate Student. 
Ten-gram samples of clay from the Guelph and Haldimand soils, as well as the standard montmorillonite and illite clays, were placed in 100milliliter polyethylene centrifuge tubes. Fifty milliliters of MTPS were added, and the suspension was shaken on a wrist action shaker for 24 hours. Suspensions were centrifuged, and the supernatant liquid removed. Six successive treatments were given each of the clay samples.

The clay residues were washed three times with deionized distilled water, followed by one washing with 50 per cent ethanol, and two with 95 per cent ethanol. After careful transfer to an evaporating dish, samples were dried on a steam plate, then oven-dried and weighed.

Total analyses were carried out, using the methods of Atkinson et al. (1), with the following modifications. Aluminium was determined by a versenate titrimetric method (22), total iron by the method of Cheng et al. (3), and free iron by the method of Mackenzie and Mitchell (16). Magnesium and calcium were titrated with versenate at $\mathrm{pH} 10$, using Erichrome Black $\mathrm{T}$ as the indicator. Magnesium values were found by subtracting the calcium analysis obtained previously. Loss-on-ignition values were obtained by heating samples to $750^{\circ} \mathrm{C}$. for 30 minutes.

Cation exchange capacity was determined by a semi-micro-centrifuge technique, using potassium acetate to saturate the complex (9).

$\mathrm{X}$-ray diffraction analyses were run on a Philips stabilized X-ray generator, using a copper X-ray tube. A Philips Debye-Scherrer powder camera with special collimators allowed the measurement of d-spacings up to $40 \AA$.

Clay samples were saturated with magnesium and potassium and solvated with glycerol in benezene, then air-dried and powdered (9). Heating treatments of $110^{\circ} \mathrm{C}$. and $500^{\circ} \mathrm{C}$. on potassium-saturated samples were also employed.

Differential thermal analyses (D.T.A.) were run on a modified Philips model F.I.B. Deltatherm apparatus. Samples of clay were calcium saturated and kept at a relative humidity of 44 per cent prior to analysis. The heating rate was $10^{\circ} \mathrm{C}$. per minute and the same pair of wells was used for all runs.

Electron micrographs were obtained using a Philips $75 \mathrm{~B}$ electron microscope. Dialyzed clay samples were diluted to obtain clay suspensions of 0.005 per cent. A drop of the suspension was then placed on a film of collodion supported by a 3.05-millimeter copper grid, and dried over $\mathrm{CaCl}_{2}$.

TABLE 1. - LOSS IN WEIGHT OF CLAY SAMPLES AFTER TREATMENT WITH MTPS

\begin{tabular}{l|c}
\hline Clay sample & Loss in weight (\%) \\
\hline Guelph & 59.5 \\
Haldimand & 40.4 \\
Montmorillonite & 3.4 \\
Illite & 8.1 \\
\hline
\end{tabular}




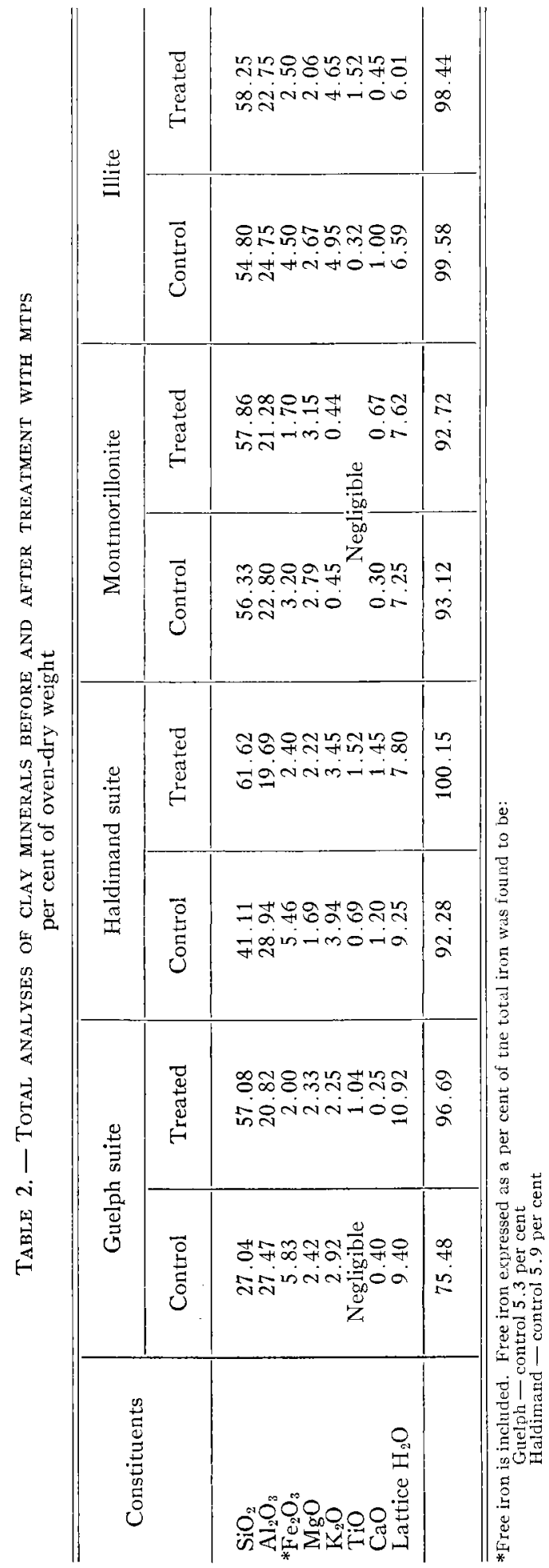




\section{RESULTS AND DISCUSSION}

The losses in weight of the clay samples upon treatment with MTPS were much larger in the natural clay separates, and largest in the Guelph separate (Table 1).

Total analyses (Table 2) were similar to published data (7) for $2: 1$ clay minerals, except for the low silica content in the Guelph control sample. This value was repeatedly checked but no satisfactory explanation found. As a result of the MTPS treatment there was a decrease in aluminium, iron and potassium, but an increase in the percentage of silica. There were several indications of the destruction of clay minerals, as well as the removal of amorphous material.

1. Iron removed by the MTPS must have come largely from the crystal lattice because losses greatly exceeded the amount of free iron present in the clays.

2. Potassium lost upon treatment could have come from the clay lattice positions as no exchangeable potassium was present prior to treatment with MTPS. The possible solution of small amounts of clay-size feldspars cannot be discounted, however.

3. Further evidence of lattice decomposition was the marked reduction in cation exchange capacity. The cation exchange capacity of the Guelph clay sample decreased from 82 to $29 \mathrm{mc} . / 100 \mathrm{~g}$. and of the Haldimand clay samples from 46 to $21 \mathrm{me} . / 100 \mathrm{~g}$. If only adsorbed iron and aluminium had been removed the cation exchange capacity of the residue should have increased (21).

$\mathrm{X}$-ray diffraction data (Table 3) indicated the presence of illite, vermiculite and interstratified montmorillonite-illite structures in the Guelph clay separate (2). The presence of a weak $9.25 \AA$ A diffraction line in the magnesium-saturated sample that persisted upon heating to $500^{\circ} \mathrm{C}$. indicated illite clay minerals. There was no $18 \dot{\mathrm{A}}$ diffraction line to indicate montmorillonite. However, the possibility of interstratified illite-montmorillonite structures was indicated by a broad $14 \AA$ line that persisted after potassium saturation but disappeared upon heating to $500^{\circ} \mathrm{C}$. Vermiculite was indicated by the relative decrease in intensity of the $14 \AA$ line and increase in the $10 \AA$ line upon potassium saturation. The complete disappearance of the $14 \AA$ diffraction line upon heating to $500^{\circ} \mathrm{C}$. showed the absence of chlorites.

Estimates of the illite content were made from the total $\mathrm{K}_{2} \mathrm{O}$ values. Values for pure illite of 10 per cent $\mathrm{K}_{2} \mathrm{O}$ (9), and 6 per cent $\mathrm{K}_{2} \mathrm{O}$ (7) were used to determine the range in each sample. The total chemical analyses indicated that the illite content ranged from 29 to 50 per cent in the Guelph clay separate. Montmorillonite was not detected on D.T.A., and vermiculite was not estimated.

The treated sample of Guelph clay had sharper X-ray diffraction patterns and more pronounced differential thermal peaks (Figure 1). The removal of amorphous iron and aluminium compounds and of small imperfect crystals could produce this result. Also, according to Mering (18), the extraction of lattice aluminium from montmorillonite may produce a silica skeleton with similar dimensions to the original silica sheets. Presumably 


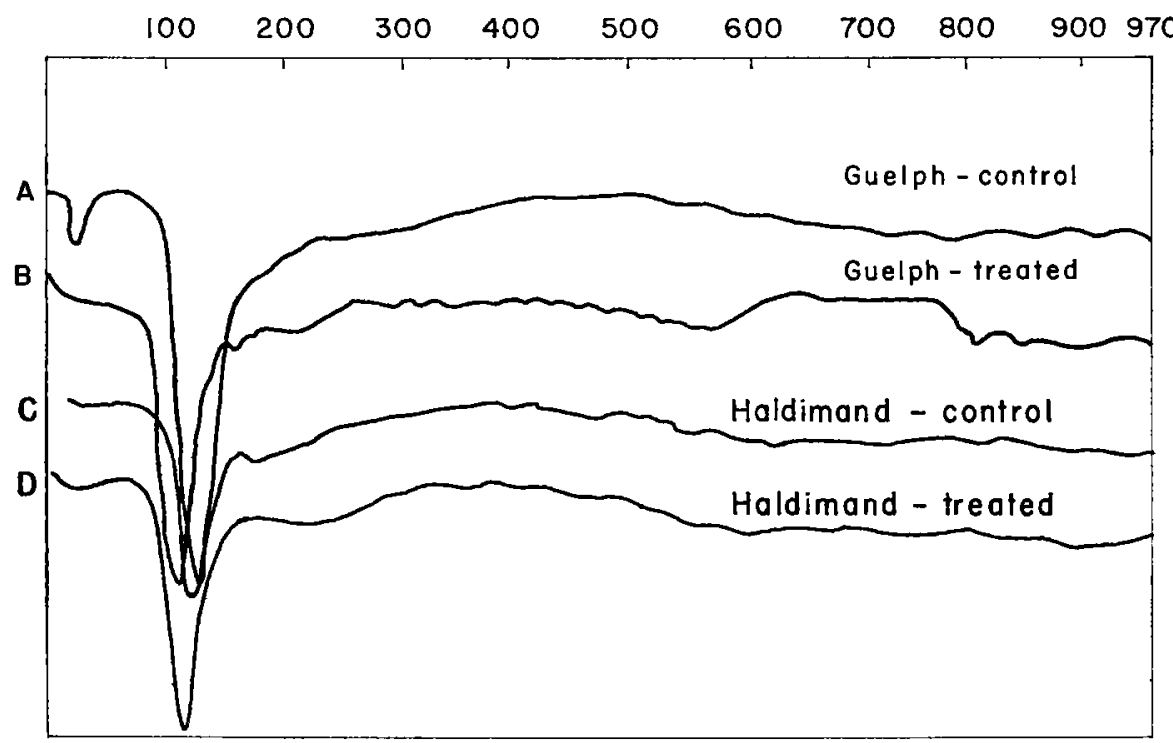

Figure 1. Differential thermal analyses of the Guelph and Haldimand clay separates before and after treatment with MTPS.

this could occur with the 2:1 clay minerals present in these samples. Also, the reduction in iron content reduced the iron fluorescence caused by the copper radiation and hence the background in the X-ray diffraction patterns was lower.

The diffraction analyses of the treated Guelph clay (Table 3) indicated that illite was present. Vermiculite was present as shown by the decrease in the $14 \bar{A}$ diffraction line upon potassium saturation. The proportion of vermiculite and interstratified montmorillonite in the treated clay was less than in the untreated clay. This was indicated by a stronger $10 \AA$ line compared to the $14 \overline{\mathrm{A}}$ line in the magnesium-saturated treated sample than in the comparable untreated clay sample. The total $\mathrm{K}_{2} \mathrm{O}$ content was lower in the treated sample indicating an illite content of 23 to 38 per cent. If the $600^{\circ} \mathrm{C}$. endotherm was indicative of illite, more illite was detected in the treated sample (6) (Figure 1). Thus a partial removal of potassium from the illite lattices may have occurred upon treatment with MTPS.

In the Haldimand clay separate illite was the dominant clay mineral as evidenced by the strong $10 \bar{A}$ line and high potassium content. Fstimates of the illite concentration ranged from 39 to 66 per cent as calculated from the total $\mathrm{K}_{2} \mathrm{O}$ analysis. The presence of a small amount of vermiculite was indicated by the almost complete disappearance of the $14 \AA$ line upon potassium saturation. This also indicated that very little or no interstratified montmorillonite was present. Electron micrographs (Figure 2) showed cylindrical crystals of the dimensions and configuration of halloysite (7). 


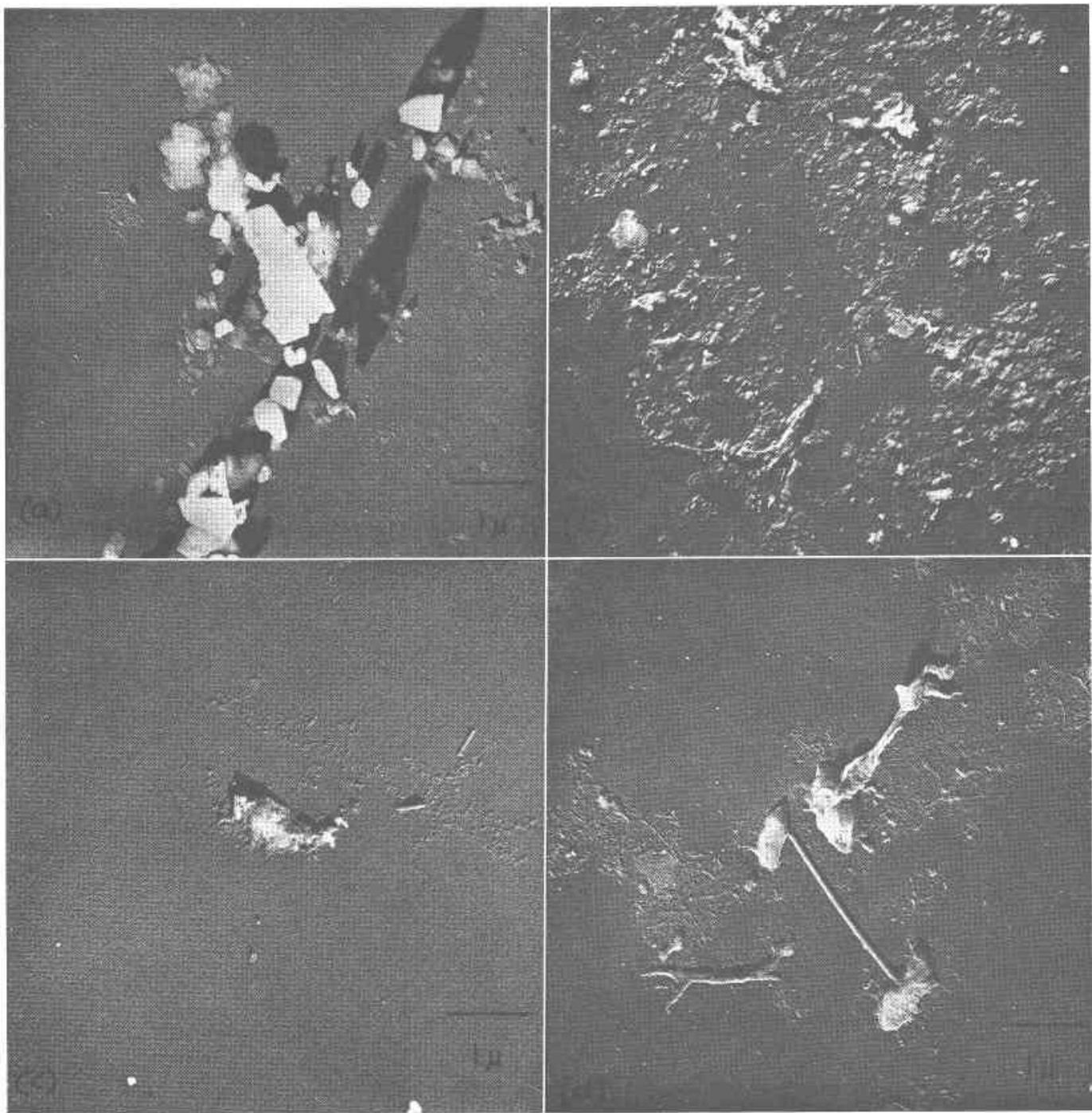

Figire 2. Electron microscopic pictures of Guelph control (top left); Guelph treated (top right); Haldimand control (lower left); and Haldimand trcated (lower right) samples. 
August, 1963] MACKENZIE AND CAMPBELL-META-STARLE SOLUTION

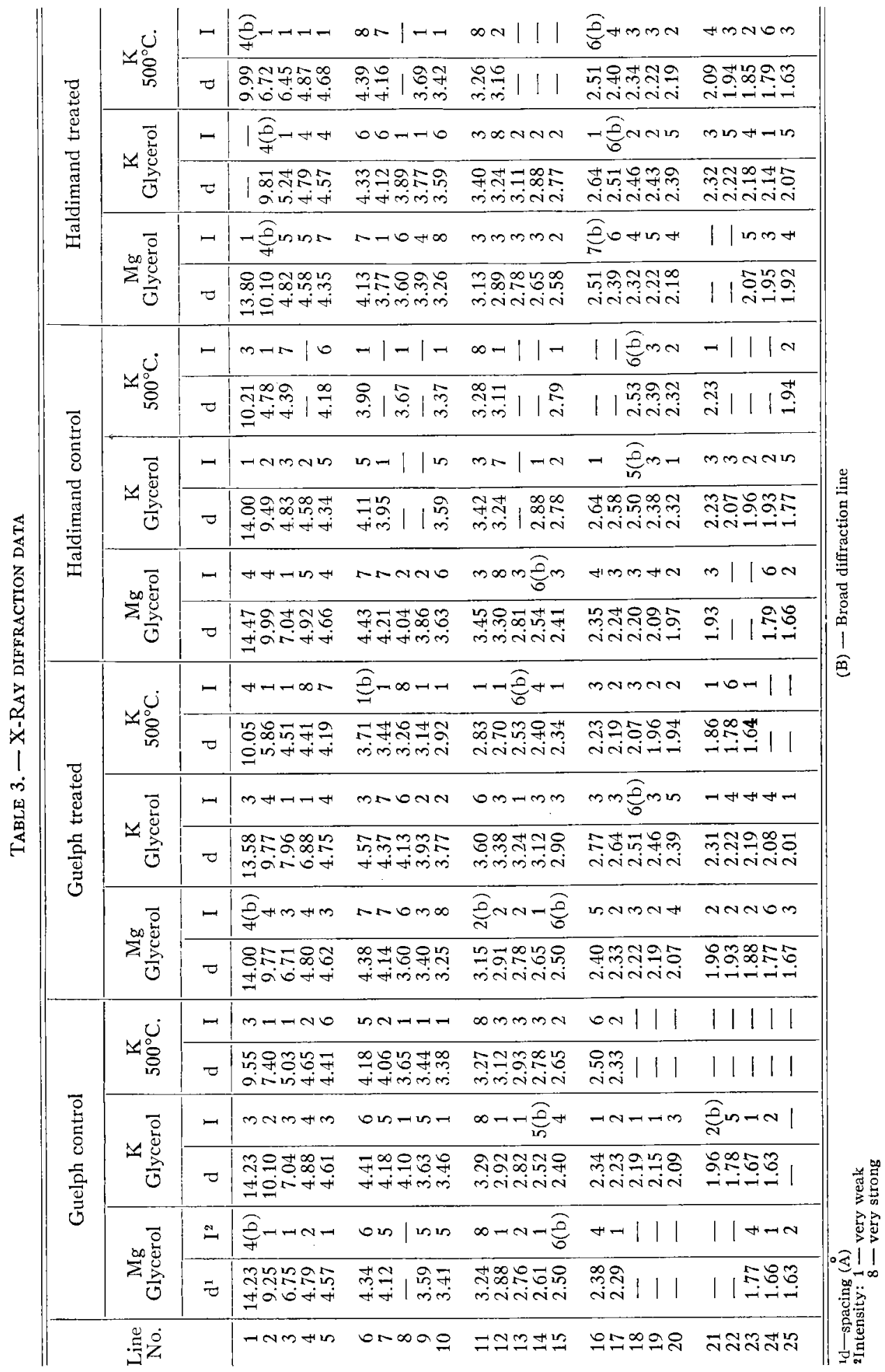


The treated Haldimand clays were also dominated by illite as the $10 \AA$ diffraction line was pronounced. Estimates of the illite content ranged from 35 to 58 per cent from the chemical analysis. The $14 \AA \mathrm{A}$ diffraction line compared with the $10 \bar{A}$ line was much weaker in the treated clay sample and completely disappeared upon potassium saturation. It was concluded that no interstratified montmorillonite was present and that the proportion of vermiculite had been reduced by treatment with MTPS. An halloysitelike crystal was again noted in the electron micrograph (Figure 2).

\section{CONCLUSIONS}

On the basis of the data obtained from the soil clay separates, it was concluded that vermiculite and montmorillonite-type clays were more susceptible to treatment with MTPS than illite and halloysite clays. However, some alteration of illite may have occurred by removal of potassium from the lattice. Thus the treatment may have more influence on the expanding lattice type of crystal possibly because of the larger specific surface of these clays.

The physical effects of the treatment are shown by comparisons of the electron micrographs (Figure 2). Treated samples of both the standard clays and the soil clay separates had more small particles. Partial physical disintegration of the clay by removal of some of the lattice constituents of the lattice may have occurred, although the extra shaking received by the treated samples may have caused some particle size reduction as well.

\section{ACKNOWLEDGEMENTS}

The authors would like to thank the Department of Chemistry, University of Waterloo, for the use of their X-ray equipment. The financial assistance of Agricultural Chemicals Limited is also acknowledged.

\section{REFERENCES}

1. Atkinson, H. J., G. R. Giles, A. J. MacLean, and J. R. Wright. 1958. Chemical methods of soil analysis. Contrib. No. 169, Chemistry Division, Science Service, Canada Dept. of Agriculture, Ottawa.

2. Brindley, G. W. 1951. X-ray identification and crystal structure of clay minerals. Monogr., Mineralogical Soc. Great Britain.

3. Cheng, K. L., R. H. Bray, and T. Kurtz. 1953. Determination of total iron in soils by disodium dihydrogen ethylene diamine tetraacetate titration. Anal. Chem. 25:347-348.

4. Coleman, R. 1942. The adsorption of phosphate by kaolinite and montmorillonite. Soil Sci. Soc. Amer. Proc. 7:134-138.

5. Ensminger, L. E. 1948. The relationship between water lost and phosphate adsorbed on phosphating clay minerals and soil colloids. Soil Sci. Soc. Amer. Proc. 13: $170-174$.

6. Grim, R. E. 1947. Differential thermal curves of prepared mixtures of clay minerals. Amer. Mineralogist 32:493-501.

7. Grim, R. E. 1953. Clay mineralogy. McGraw-Hill Book Co., Toronto, Ont.

8. Haseman, J. F., E. H. Brown, and C. D. Whitt. 1950. Some reactions of phosphate with clays and hydrous oxides of iron and aluminium. Soil Sci. 70:257-271.

9. Jackson, M. L. 1956. Soil chemical analysis-advanced course. Published by the author, Dept. of Soils, University of Wisconsin, Madison, Wis.

10. Kittrick, J. A., and M. L. Jackson. 1955. Rate of phosphate reaction with soil minerals and electron microscope observations on the reaction mechanism. Soil Sci. Soc. Amer. Proc. 19:292-295. 
11. Lehr, J. R., W. E. Brown, and E. H. Brown. 1959. Chemical behavior of M.C.P. monohydrate in soils. Soil Sci. Soc. Amer. Proc. 23:3-7.

12. Lindsay, W. L., and H. F. Stephenson. 1959. Nature of the reaction of M.C.P. monohydrate in soils: I. The solution that reacts with the soil. Soil Sci. Soc. Amer. Proc. 23:12-17.

13. Lindsay, W. L., and H. F. Stephenson. 1959. Nature of the reactions of M.C.P. monohydrate in soils: II. Dissolution and precipitation reactions involving iron, aluminum, manganese and calcium. Soil Sci. Soc. Amer. Proc. 23:18-22.

14. Lindsay, W. L., J. H. Lehr, and H. F. Stephenson. 1959. Nature of the reactions of M.C.P. monohydrate in soils: III. Studies with metastable triplepoint solution. Soil Sci. Soc. Amer. Proc. 23:342-345.

15. Low, P. F., and C. A. Black. 1948. Phosphate induced decomposition of kaolinite. Soil Sci. Soc. Amer. Proc. 12:180-184.

16. Mackenzie, R. C., and B. D. Mitchell. 1954. Removal of free iron oxide from clays. Soil Sci. 77:173-184.

17. Malquori, A., L. Radelli, and S. Cecconi. 1958. The release of potassium from illite in contact with concentrated phosphate solutions. Agrochemica 3:16-28.

18. Mering, J. 1949. Les reactions de la montmorillonite. Bull. de la Soc. Chimique de France, pp. 218-223.

19. Perkins, A. T. 1958. Effect of phosphate on the C.E.C. of minerals and soils. Soil Sci. Soc. Amer. Proc. 22:509-511.

20. Roy, Rustum. 1954. The application of phase equilibrium data to certain aspects of clay mineralogy. Clays and Clay Minerals, Proc. 2nd Intern. Conf. 124-140.

21. Sawhney, B. L. 1960. Weathering and aluminium interlayers in a soil catena. Hollis-Charlton-Sulton-Leicester. Soil Sci. Soc. Amer. Proc. 24:221-225.

22. Theis, M. 1955. Direct titration of aluminum with ethylene diamine tetraacetic acid. Z. Anal. Chem. 144:106-108.

23. Wada, K. 1959. Reaction of phosphate with allophane and halloysite. Soil Sci. 87:325-330.

24. Webber, L. R., and J. A. Shivas. 1953. The identification of clay minerals in some Ontario soils: I. Parent materials. Soil Sci. Soc. Amer. Proc. 17:96-99. 